\title{
A Self-Activation Hypothesis of Affective Reactions to Fair and Unfair Events: Evidence for Supraliminal and Subliminal Processes
}

\author{
Kees van den Bos $\cdot$ Joost Miedema $\cdot$ Riël Vermunt $\cdot$ \\ Frederike Zwenk
}

Published online: 15 January 2011

(C) The Author(s) 2011. This article is published with open access at Springerlink.com

\begin{abstract}
Building and extending on justice theories and work on self-regulation, the current paper proposes a self-activation hypothesis of affective reactions to fair and unfair events, stating that in circumstances in which people's selves are activated, stronger affective reactions to fair and unfair events are more likely, compared to circumstances in which people's selves are not or less strongly activated. Findings of two experiments indeed show that simply activating the self (supraliminally or even subliminally) amplifies affective reactions to fair and unfair procedures (Experiment 1) and fair and unfair outcomes (Experiment 2). These findings thus reveal the important role of activation of the self for understanding fairness reactions. In the discussion, we note the relevance of our self-activation hypothesis for insights into different accounts formulated in the justice domain.
\end{abstract}

Keywords Justice $\cdot$ Fairness $\cdot$ Self-activation $\cdot$ Procedures $\cdot$ Outcomes $\cdot$ Affective reactions

\footnotetext{
K. van den Bos $(\bowtie)$

Department of Social Psychology, Utrecht University, Heidelberglaan 1, 3584 CS Utrecht,

The Netherlands

e-mail: k.vandenbos@uu.nl

J. Miedema

Staff Office Education and Applied Research, Hanze University Groningen, Groningen,

The Netherlands

R. Vermunt

Department of Social and Organizational Psychology, Leiden University, Leiden, The Netherlands

F. Zwenk

Justice Administration, Legislation, International and Aliens Affairs Division, Research and Documentation Centre of the Dutch Ministry of Justice, The Hague, The Netherlands
} 
People are self-regulators (e.g., Sedikides, De Cremer, Hart, \& Brebels, 2009). One way in which people may try to regulate their selves is by using fairness judgments in processes of self-regulation ${ }^{1}$ (e.g., De Cremer \& Sedikides, 2005; Van den Bos \& Lind, 2002, 2009). For example, it has been argued that when people feel uncertain about themselves (Van den Bos, Poortvliet, Maas, Miedema, \& Van den Ham, 2005) that they then start to manage their feelings of uncertainty by relying on perceptions of fair treatment (Van den Bos \& Lind, 2002). Being treated fairly may communicate to people that there is less reason to feel uncertain about themselves (Van den Bos, Heuven, Burger, \& Fernández Van Veldhuizen, 2006) or may lead them to better tolerate the personal uncertainty (Van den Bos \& Lind, 2009). This is one way in which the experience of fair or unfair treatment seems to be involved in processes of self-regulation.

Furthermore, managing personal uncertainty by means of fairness judgments in all likelihood involves "hot cognitive" processes (Van den Bos, 2007; cf. Abelson, 1963; Stapel, 2003). In correspondence with this line of reasoning, research findings indicate that when personal uncertainty is salient people react with stronger affective reactions to events they perceived as fair or unfair, compared to when personal uncertainty is not salient. For instance, Van den Bos (2001) showed that when personal uncertainty is salient participants reacted with stronger negative affective reactions toward their treatment when the procedure used in the experiment was unfair (participants were not allowed an opportunity to voice their opinions about an important decision to be made in the experiment) as opposed to fair (participants were allowed a voice opportunity). Following this line of research, the current paper will study people's negative affective reactions to fair and unfair procedures (Experiment 1) and fair and unfair outcomes (Experiment 2).

Recently it has been argued that these and other findings suggest that affective reactions to fair and unfair events probably have something to do with processes of self-regulation (e.g., Brebels, De Cremer, \& Sedikides, 2008; Miedema, Van den Bos, \& Vermunt, 2006; Van den Bos, Ham, Lind, Simonis, Van Essen, \& Rijpkema, 2008; Van den Bos \& Lind, 2002, 2009; Van Prooijen \& Zwenk, 2009). For example, Miedema et al. (2006) proposed that fairness can be a means of selfdefense and that situations that are threatening to the self therefore should lead people to react in stronger affective terms to fair and unfair events. In correspondence with this proposition, Miedema et al. show that asking participants to think about things that are threatening to themselves (not being intelligent or not being liked by friends) leads to stronger negative affective reactions to manipulations of procedural and distributive fairness.

Furthermore, Van den Bos et al. (2008) argued that the self-regulatory effects of uncertainty and self-threats briefly described here occur because personal uncertainty and self-threats often are alarming experiences. Building on this assumption, Van den Bos et al. proposed that justice reactions should be influenced reliably by

\footnotetext{
${ }^{1}$ When using the term "self-regulation" we follow the definition by Vohs and Baumeister (2004) who noted in their Handbook of Self-Regulation that "self-regulation refers to the many processes by which the human psyche exercises control over its functions, states, and inner processes." Furthermore, "selfregulation is an important key to how the self is put together. Most broadly, it is essential for transforming the inner animal nature into a civilized human being" (Vohs \& Baumeister, 2004, p. 1).
} 
the activation of psychological systems that people use to detect and handle alarming situations (Eisenberger, Lieberman, \& Williams, 2003). It was further reasoned that if this line of reasoning is true then presenting alarm-related stimuli to people should lead to more extreme reactions to subsequent justice-related events than not presenting these alarming stimuli. Findings reported by Van den Bos et al. provide evidence supporting these predictions.

Thus, it has been found in the justice literature that personal uncertainty (Van den Bos, 2001) and other self-threatening (Miedema et al., 2006) or alarming conditions (Van den Bos et al., 2008) lead to more extreme reactions to procedural and outcome justice. Van den Bos and Lind (2002, 2009) recently reviewed these and other findings and, after doing so, proposed that several studies and theories suggest that one of the reasons why fairness is important to people, and hence why fair and unfair events may be influencing people's affective reactions, is because fairness communicates important information about people's selves (see also Brockner, 2002; Koper, Van Knippenberg, Bouhuijs, Vermunt, \& Wilke, 1993; Sedikides et al., 2009; Van den Bos, Bruins, Wilke, \& Dronkert, 1999; Van Prooijen \& Zwenk, 2009). In other words, experienced fairness may have some special qualities that cause fair and unfair events to have an especially strong impact on affective reactions when people are uncertain about themselves (Van den Bos, 2001), when their selves have been threatened (Miedema et al., 2006), or when they find themselves in alarming conditions (Van den Bos et al., 2008). As a result, fair events may make people respond in positive terms to conditions of personal uncertainty, self-threats, or alarming situations, whereas unfair events may cause people to react especially negatively toward these self-related conditions. According to Van den Bos and Lind $(2002,2009)$, the experience of fair or unfair events seems thus to be involved in processes of self-regulation. According to these authors, this is a key reason why fairness may play an important role in affective self-regulatory processes, as a result of which people's affective reactions to fair and unfair events may be intimately associated with processes of self-regulation (see also Van den Bos, 2007).

\section{The Current Research}

In the present paper, we argue that if, as the Van den Bos and Lind (2002, 2009) reviews suggest, people's affective reactions to fair and unfair treatment indeed are intimately associated with processes of self-regulation (Van den Bos, 2007), then it should be the case that the tendency to be influenced in one's affective reactions by fair and unfair events should be stronger in conditions in which self-related cognitions are accessible or activated. Thus, on the basis of this line of reasoning we propose that in circumstances in which people's selves are activated, stronger affective reactions to fair and unfair events are more likely, compared to circumstances in which people's selves are not or less strongly activated. This suggests that simply activating the self (supraliminally or even subliminally) should be enough to increase fairness effects on affective reactions. Simply put, selfactivation may amplify people's affective reactions to fair and unfair procedures and 
fair and unfair outcomes. To our knowledge, this self-activation hypothesis has never been articulated explicitly or tested directly. In the present two experiments, we hope to fill this void and put the hypothesis to a direct test. In doing so, selfactivation was induced by means of a supraliminal manipulation in Experiment 1 and a subliminal manipulation in Experiment 2.

More specifically, in our first experiment we show that activation of the general self (by asking participants to complete two simple open-ended questions that remind them of themselves) leads to amplified affective reactions to fair versus unfair procedures (viz., voice vs. no-voice procedures). In our second experiment we show that subliminal activation of the personal or individual self can lead to affective amplification regarding fair and unfair outcomes (viz., outcomes that are equal to the outcome of a comparable other person or worse than the other's outcome).

Besides the reasons mentioned earlier, we think it is interesting to investigate our hypothesis because it may move the attention from what the differences are between self-regulatory processes following personal uncertainty (e.g., Van den Bos, 2001), self-threats (e.g., Miedema et al., 2006), and alarming conditions (e.g., Van den Bos et al., 2008) to what these processes have in common. We note here that the effects of personal uncertainty, self-threats, and conditions that are alarming to the self all have been assumed to rely (at least partly) on activation of the self. Thus, personal uncertainty, self-threats, and events that are alarming to people may be different in important aspects, but all have activation of the self in common. An important aim of the current paper is to study the effects of this common denominator on people's affective reactions to fair and unfair events. We try to achieve this aim by simply activating the self (supraliminally or subliminally), independently of uncertainty concerns, self-threats, or alarming events. How and in which ways our research extends beyond very recent developments in the justice literature (e.g., Van Prooijen $\&$ Zwenk, 2009) will be explained after we have discussed the findings of our first experiment.

\section{Experiment 1: Supraliminally Activating the General Self}

In Experiment 1, building on previous experiments (e.g., Van den Bos et al., 2005), we induced a general self-activation by means of two open-ended questions that asked participants to think about themselves. Following earlier studies, participants in the control conditions were asked to think about watching television (e.g., Van den Bos et al., 2005). In Experiment 1, participants took part in an experiment in which they either received an opportunity to voice their opinions about a decision that had to be made in the experiment or did not receive such an opportunity (cf. Van den Bos, 2001). In this paper we are interested in assessing processes of affective self-regulation (Van den Bos, 2007; Van den Bos \& Lind, 2009). Furthermore, because it is important to measure affective reactions toward perceived fairness (Tyler \& Smith, 1998), and especially negative affect (Folger \& Cropanzano, 1998), the main dependent variables were measures of negative affect about the way participants felt treated in the experiment. 


\section{Method}

\section{Participants and Design}

Ninety-seven students ( 22 men and 75 women $)^{2}$ at Leiden University participated in the experiment. Participants were randomly assigned to one of the conditions of the 2 (salience: self vs. television) $\times 2$ (procedure: voice vs. no voice) factorial design.

\section{Experimental Procedure}

Students at Leiden University were invited to participate in a study on how people perform tasks. The experiment lasted a total of $50 \mathrm{~min}$ and participants were paid 5 Euros for their participation. On arrival at the laboratory, participants were led to separate cubicles, each of which contained a personal computer. All instructions were given by means of the computer.

In the first part of the instructions, participants were informed that they participated in the experiment with another person, referred to as Other. The experimental procedure was then explained to the participants. After an explanation of the experimental tasks, participants were to practice the tasks for 2 min, after which they would work on the tasks for $10 \mathrm{~min}$. Participants were also informed that after all participants had been run, a lottery would be held among all participants. The winner of this lottery would receive 50 Euros (actually, after all participants had completed the experiment, the 50 Euros were randomly given to one participant; none of the participants objected to this experimental procedure upon debriefing). Participants were told that a total of 200 lottery tickets would be divided among all participants. Furthermore, participants were told that after the work round the experimenter would divide some lottery tickets between them and Other. Seven practice questions were asked to ensure comprehension of the lottery. If a participant gave a wrong answer to a question, the right answer was shown and the main characteristics of the lottery were repeated. The task was then explained to the participants. This task was the same as in Van den Bos (2001, Experiment 1).

After completing the practice and work rounds, participants were told the number of tasks they had completed in the work round. To ensure that participants compared themselves to Other, the participants were informed that Other had completed an equivalent number of tasks. To assess whether participants thought of Other as a person who was comparable in the amounts of inputs he or she provided, they were asked to what extent Other had performed well in the work round relative to the performance of participants themselves, to what extent Other did his or her best in the work round relative to the participants themselves, and to what extent Other was good in performing the tasks in the work round relative to the participants themselves $(1=$ much worse, $4=$ equally, $7=$ much better $)$. After answering these questions, participants were asked to think for $1 \mathrm{~min}$ about the percentage of lottery tickets that they should receive relative to Other.

\footnotetext{
${ }^{2}$ Gender yielded no main or interaction effects on our dependent variables and manipulation checks, and was dropped from the analyses.
} 
Participants were then informed that before the experimenter would divide the lottery tickets between them and Other, they would be asked to complete some questions and that after the questions were answered, the study would continue. Building on previous salience studies (e.g., Miedema et al., 2006; Van den Bos, 2001; Van den Bos et al., 2005), participants in the self-salient condition were asked to respond to two open-ended questions: (1) "Please briefly describe the emotions that arise in you when you think of yourself" and (2) "Please write down, as specifically as you can, what you think physically will happen to you as you think of yourself." Participants in the control condition were asked two questions that were similar in format and that asked participants about watching television (see, e.g., Miedema et al., 2006; Van den Bos, 2001). After this, all participants completed the Positive And Negative Affect Schedule (PANAS; Watson, Clark, \& Tellegen, 1988) on which they reported on 20 items how they felt at the moment. Following previous studies (e.g., Miedema et al., 2006; Van den Bos, 2001; Van den Bos et al., 2005), the PANAS was included as a filler task and to determine whether the salience manipulation engendered positive or negative affect. The PANAS consists of two 10-item subsets (Watson et al., 1988), one measuring positive affect (PA) and one measuring negative affect (NA). Both the PA scale and the NA scale were averaged to form reliable scales (both alpha's $=.80$ ). After they had completed the PANAS, all participants were told that by pushing the return button on the keyboard the study would continue.

The procedure was then manipulated. In the voice condition, the experimenter allegedly asked participants to type in their opinion about the percentage of tickets that they should receive relative to Other. Participants in the no-voice condition were informed that they would not be asked to type their opinion about the percentage of tickets that they should receive relative to Other. After this, participants were asked questions pertaining to the dependent variables and manipulation checks. All ratings were made on 7-point scales. Main dependent variables were ratings of negative procedural affect: Participants were asked how angry $(1=$ not at all angry, $7=$ very angry) and furious ( $1=$ not al all furious, $7=$ very furious $)$ they felt about the way they were treated in the experiment. These ratings were averaged to form a reliable scale of negative procedural affect (alpha $=.79$ ).

Following previous studies (e.g., Van den Bos, 2001; Van den Bos et al., 2005), the procedure manipulation was checked by assessing participants' ratings of procedural fairness: Participants were asked how fair $(1=$ very unfair, $7=$ very fair $)$ and just $(1=$ very unjust, $7=$ very just $)$ they thought the way they were treated was. These judgments were averaged to form a reliable procedural fairness scale (alpha $=.96$ ). The manipulation of procedure was further checked by asking participants to what extent they agreed with the statement that they had been given an opportunity to voice their opinion about the percentage of tickets that they should receive relative to Other $(1=$ strongly disagree, $7=$ strongly agree $)$ and to what extent they agreed with the statement that they had not been given an opportunity to voice their opinion about the percentage of tickets that they should receive relative to Other $(1=$ strongly disagree, 7 = strongly agree). When the participants had answered these voice and no-voice checks, they were debriefed and paid for their participation. 
Results

\section{Manipulation Checks}

A 2 (salience) $\times 2$ (procedure) multivariate analysis of variance (MANOVA) on the two manipulation checks of procedure (the voice check and the no-voice check) yielded only main effects of procedure at the multivariate and univariate levels, multivariate $F(2,92)=466.89, p<.001, \eta^{2}=.91$; for the voice check, $F(1$, $93)=943.60, p<.001, \eta^{2}=.91$; for the no-voice check, $F(1,93)=405.35$, $p<.001, \eta^{2}=.81$. Participants in the voice condition agreed more with the statement that they received an opportunity to voice their opinion $(M=6.3$, $S D=1.1)$ than participants in the no-voice condition $(M=1.1, S D=0.3)$. Participants in the no-voice condition agreed more with the statement that they did not receive an opportunity to voice their opinion $(M=6.6, S D=1.2)$ than participants in the voice condition $(M=1.7, S D=1.2)$. This indicates that procedure was successfully operationalized.

Participants' procedural fairness judgments yielded only a main effect of procedure, $F(1,93)=120.80, p<.001, \eta^{2}=.57$. Participants in the voice condition judged the procedure to be more fair $(M=5.6, S D=1.2)$ than participants in the no-voice condition $(M=2.9, S D=1.2)$. This shows that the manipulation of procedure was successful in influencing participants' fairness judgments in ways that were intended with this manipulation. The main effect of the salience manipulation and the interaction effect were not significant, both $F \mathrm{~s}<1$, $p s>.35, \eta^{2} \mathrm{~s}<.01$.

In the self-salient conditions, participants were asked to write down their responses when they thought of themselves, and participants in the television salient conditions were asked to write down answers pertaining to watching television. To assess whether these questions did not lead participants to think about self-threats, personal uncertainty, or any other issues besides themselves or television, two judges coded whether the answers that participants wrote down were consistent with the topics under consideration. Independently of each other the judges agreed that all answers were self- or television-related and that none of the answers were related to self-threats or alarming conditions. Interestingly, some participants (6) wrote down answers that were related to personal uncertainty. However, excluding the data of these participants did not lead to different conclusions and therefore the data of these participants were not removed from the data set. These findings indicate that, as expected, thoughts related to self-threats, uncertainty, or alarming events cannot explain the findings reported here.

\section{PANAS Findings}

A $2 \times 2$ ANOVA on participants' scores on the PANAS scales yielded no significant effects. Overall means of the PA and NA scales were $2.9(S D=0.6)$ and $1.3(S D=0.4)$, respectively. Furthermore, controlling for the PANAS scores did not influence the effects of our manipulations on the dependent variable to be reported below. Thus, in correspondence with earlier studies (e.g., Van den Bos, 
2001), differences in affective states as a result of the salience manipulation cannot explain the findings reported here.

\section{Comparability Measures}

A $2 \times 2$ ANOVA on participants' comparability judgments yielded no significant effects at either the multivariate or univariate levels. Participants indicated that the other participant had performed equally well in the work round $(M=3.9$, $S D=0.4)$, that the other participant equally did his or her best in the work round $(M=4.0, S D=0.1)$ and that the other participant was equally good in performing the tasks in the work round $(M=3.9, S D=0.4)$. These means did not differ significantly from " 4 ", the midpoint of the scale. Thus, participants considered the other person to be comparable with respect to the tasks that were completed in the experiment.

\section{Percentage Findings}

Participants who were allowed voice $(n=49)$ typed in their opinion about the percentage of lottery tickets that they should receive relative to the other participant. An ANOVA yielded no significant effect of the salience manipulation. Forty-eight participants answered that they should receive $50 \%$ of the tickets. The mean percentage $(M=51.0, S D=7.1)$ did not differ significantly from $50 \%$. These findings corroborate equity theory (Adams, 1965): Participants preferred to divide outcomes equally between themselves and the other participant.

\section{Negative Procedural Affect}

Main dependent variables were participants' ratings of negative affect about the way they were treated. These dependent variables were assessed after both salience and procedure had been manipulated. A $2 \times 2$ ANOVA yielded only the predicted significant interaction effect between procedure and salience, $F(1,93)=4.25$, $p<.05, \eta^{2}=.04$. Means and standard deviations are displayed in Table 1. In accordance with predictions, the effect of procedure was stronger in the self-salient condition, $F(1,93)=6.50, p<.02, \eta^{2}=.07$, than in the control condition, $F<1$, $p>.70, \eta^{2}=.00$. It can also be noted that the results indicated no significant effects of salience within the voice or no-voice conditions.

\section{Experiment 2: Subliminally Activating the Individual Self}

As predicted, the findings of Experiment 1 show that the effect of the voice versus no-voice manipulation on participants' ratings of negative procedural affect was stronger in the condition in which participants' general selves had been made salient than in the control condition in which participants thought about watching television. This suggests that people react stronger toward fairness-inducing procedures after activation of their general self-concept. Before we draw any strong 
Table 1 Means and standard deviations of ratings of negative procedural affect as a function of salience and procedure (Experiment 1)

\begin{tabular}{llllll}
\hline & \multicolumn{2}{l}{ Salience } & & \multicolumn{2}{l}{ Television } \\
\cline { 2 - 3 } \cline { 4 - 6 } Procedure & Self & $S D$ & & $M$ & $S D$ \\
\cline { 2 - 6 } & $M$ & 1.0 & 2.1 & 1.3 \\
Voice & 1.5 & 1.6 & 1.9 & 1.4 \\
\hline
\end{tabular}

Note: Means are on 7-point scales, with higher values indicating higher ratings of negative affect about the way participants felt treated

conclusions on the basis of these findings, however, we think it is important to conduct a second experiment.

The findings of Experiment 1 are valuable, we think, because they show that activation of participants' general selves can lead to reliable affective amplification regarding fair and unfair procedures. According to our knowledge, the importance of the general self has not been shown this explicitly in the justice literature. This noted, the self-concept consists of many components, of course (see, e.g., Brewer \& Gardner, 1996), so in Experiment 2 we want to show that activation of a more specific component of the self could also lead to enhanced amplification with regard to people's affective reactions to fair and unfair events.

Relevant for the current purposes, Van Prooijen and Zwenk (2009) argued very recently that activation of the personal or individual self leads to increased responses to fair and unfair events. In our second experiment we build on this line of reasoning. The individual self is the part of the self-concept that differentiates the self from others and stresses the individual's uniqueness. It is an integral part of people's self-concept and can be made more or less accessible through contextual factors (Brewer \& Gardner, 1996; Gardner, Gabriel, \& Lee, 1999; Stapel \& Koomen, 2001).

Van Prooijen and Zwenk (2009) activated the individual self by asking participants to write seven sentences using words such as "I," "me," or "my" in each sentence. We argue here that priming in this way with "I" words is intriguing, but that especially strong evidence for the role of the activated individual self would be obtained when a subliminal presentation of "I" words would lead to enhanced reactions to fair and unfair events among participants.

Therefore, in Experiment 2 we used a subliminal manipulation to activate the individual self-concept. Specifically, whereas the salience-evoking questions of Experiment 1 made participants actively and consciously think about emotions concerning their general selves, and whereas the Van Prooijen and Zwenk (2009) activated the individual self in a conscious manner, in Experiment 2 we presented self-related words ("I," "me," and "my") for $20 \mathrm{~ms}$ on participants' computer screens. This presentation time is too short for the presented stimulus to enter conscious thought (Custers \& Aarts, 2005), but the presented information stays on the computer screen long enough to activate the intended psychological construct 
(the individual self). In the control conditions, non-words were presented for $20 \mathrm{~ms}$ on participants' screens. Subliminal presentation of the self-words (vs. non-words) was used for two important reasons. First, this procedure rules out the possibility of performance demands. Second, effects on participants' fairness reactions would provide evidence for non-conscious processes, as participants are unaware of the activation of their individual self-concept and its influence on their reactions.

Another reason why Experiment 2 was important was because a critic might note that in the control condition of Experiment 1 there was no significant effect found of the fairness manipulation. Therefore, an important goal of Experiment 2 was to show a significant effect of the fairness manipulation in the control condition and to assess whether the fairness effect would then still found to be stronger in the condition in which people's selves had been activated. One way in which we tried to achieve this was by using an experimental procedure that was easier to follow for participants than the experimental procedure used in Experiment 1 (in which the experiment was stopped, salience was manipulated, after which the experiment continued and fairness reactions were assessed). Experiment 2 was presented as two unrelated studies. In the first study, the self-activation manipulation was induced. The second study was ostensibly unrelated to the first and in it participants read and responded to the fairness manipulation.

In Experiment 1, we used the concept of procedural fairness (voice vs. no voice) as our fairness manipulation. Van Prooijen and Zwenk (2009) used a similar manipulation. Because fairness constitutes not only the process leading to outcome distributions, but the actual outcome distribution as well (Adams, 1965), it was important to show evidence for our self-activation hypothesis using a manipulation of distributive justice. Participants in Experiment 2 were therefore informed that they received an outcome that was either equal to or worse than the outcome of a comparable other person.

\section{Method}

\section{Participants and Design}

Fifty-one students (22 men and 29 women) at Leiden University participated in the experiment. Participants were randomly assigned to one of the conditions of the 2 (subliminal stimuli: self-related words vs. non-words) $\times 2$ (outcome: equal to other vs. worse than other) factorial design.

\section{Experimental Procedure}

The experiment was preceded by another, unrelated study. The experiments lasted a total of $50 \mathrm{~min}$ and participants were paid 4.50 Euros. Our experiment was presented to the participants as two separate studies. In the first study, the subliminal self-activation manipulation was induced following the paradigm by Coenen, Dijksterhuis, and Wigboldus (2003): Participants were informed that they would 
participate in a recognition task in which a random string of letters would appear on the computer screen and in which they were asked to indicate, as accurately and quickly as possible, whether the string started with a vowel or a consonant by pressing the appropriate button on the computer keyboard ("A" for a vowel, " 6 " on the numerical part of the keyboard for a consonant). Twenty trials were run. In each trial, a blank screen was presented for $2 \mathrm{~s}$, after which a row of Xs appeared in the center of the computer screen. This forward mask was presented for $500 \mathrm{~ms}$. This was followed by the presentation for $20 \mathrm{~ms}$ of a self-related word ("I," "me," or "my") (in Dutch: "ik," "mij," "mijn") in the self-activated conditions, or a nonword ("bd," "dbd," "dbhg") in the control conditions. In both conditions, this was immediately followed by a backward mask consisting of a random string of letters (e.g., "jhgeslhreu"). This string stayed on the computer screen until either the "A" or the " 6 " button was pressed. After pressing one of the buttons, the screen went blank and the following trial started. After the 20 trials were completed, the first study ended and the second study started.

In the second study, participants were asked to imagine the following situation (Miedema et al., 2006):

Together with a fellow student, you have had a summer job. The two of you were working as a pair. The organization you worked for has a lot of employees working in pairs. You and your fellow student have worked equally hard and have performed equally well. Because the organization has done very well that summer, it is announced at the last workday of the summer that a bonus of 10,000 Euros will be divided amongst all employees. A certain amount of bonus money has been set aside for your pair (you and your fellow student). Your supervisor still has to decide how the money, reserved for you and your fellow student, will be divided. A week later, payment of the bonus money takes place.

This was followed by the manipulation of outcome. Participants read (manipulated information in italics):

You receive 450 Euros; Your fellow student receives 450/900 Euros.

After this, participants were asked how angry $(1=$ not at all angry, $7=$ very angry) and furious $(1=$ not al all furious, $7=$ very furious $)$ they felt about the distribution of outcomes. These ratings were averaged to form a reliable scale of negative outcome affect (alpha $=.98)$. We also assessed how fair $(1=$ very unfair, $7=$ very fair $)$ and just $(1=$ very unjust, $7=$ very just $)$ participants thought the distribution of outcomes was (alpha $=.97$ ).

When participants had answered these questions, they were debriefed and paid for their participation. During the funneled debriefing, participants were checked for awareness of the subliminally presented words and non-words. This indicated that all participants were unaware of the presentation of these stimuli and none of the participants realized the true nature of our study. Furthermore, none of the participants indicated that these stimuli had influenced their responses. Thus, if effects of our self-activation manipulation on participants' responses occur, they seem to operate outside of participants' conscious awareness (Bargh \& Chartrand, 2000). 
Results

\section{Outcome Fairness}

A 2 (subliminal stimuli) $\times 2$ (outcome) ANOVA on the outcome fairness scale yielded only a reliable main effect of the outcome manipulation, $F(1,47)=870.63$, $p<.001, \eta^{2}=.95$. Participants who received an equal outcome judged their outcome to be more fair $(M=6.6, S D=0.7)$ than participants who received a worse outcome $(M=1.4, S D=0.6)$. This shows that the manipulation of outcome was induced as intended. The main effect of the self-activation manipulation and the interaction effect were not significant, both $F \mathrm{~s}<1, p \mathrm{~s}>.39, \eta^{2} \mathrm{~s}<.02$.

\section{Negative Outcome Affect}

Main dependent variables were participants' ratings of negative affect about the distribution of outcomes. These variables were measured after self-activation and outcome had both been induced. A $2 \times 2$ ANOVA on the negative affect scale yielded only a main effect of outcome, $F(1,47)=486.60, p<.001, \eta^{2}=.91$, and an interaction effect, $F(1,47)=4.33, p<.05, \eta^{2}=.08$. Means and standard deviations are presented in Table 2. The main effect of the outcome manipulation indicated that participants showed higher ratings of negative affect after receiving a worse outcome than after receiving an equal outcome. The interaction effect showed that the effect of outcome was stronger in the self-activated condition, $F(1$, $47)=276.56, p<.001, \eta^{2}=.86$, than in the control condition, $F(1,47)=213.66$, $p<.001, \eta^{2}=.82$. Additionally, it can be noted that no significant effects of selfactivation were found within the equal-to-other or worse-than-other outcome conditions.

\section{General Discussion}

The findings of Experiment 2 show that when the individual self has been activated outside of conscious awareness by subliminally presenting "I" words (as opposed to non-words) on computer screens, ratings of negative affect are significantly

Table 2 Means and standard deviations of ratings of negative outcome affect as a function of subliminally presented stimuli and outcome (Experiment 2)

\begin{tabular}{|c|c|c|c|c|}
\hline \multirow[b]{3}{*}{ Outcome } & \multicolumn{4}{|c|}{ Subliminal stimuli } \\
\hline & \multicolumn{2}{|c|}{ Self-words } & \multicolumn{2}{|c|}{ Non-words } \\
\hline & $M$ & $S D$ & $M$ & $S D$ \\
\hline Equal to other & 1.0 & 0.0 & 1.4 & 0.9 \\
\hline Worse than other & 6.4 & 0.8 & 5.9 & 1.0 \\
\hline
\end{tabular}

Note: Means are on 7-point scales, with higher values indicating higher ratings of negative affect about the outcome distribution participants responded to 
amplified regarding variations in outcomes received (equal outcomes vs. worse than other's outcomes). These findings thus reveal the importance of activation of the self in general, and the individual self in particular, for our understanding of people's reactions to fair and unfair events.

Experiment 2 is also important because in this study we were successful in obtaining a significant effect of our fairness manipulation (equal-to-other vs. worsethan-other outcomes) in our control condition (in which non-words were presented to our participants), and then getting a significant interaction effect indicating a significantly stronger effect of the fairness manipulation in our experimental condition (in which self-words were presented). Taken together, Experiments 1 and 2 suggest that both supraliminally and subliminally induced self-activation can amplify people's negative affective reactions to both procedural and distributive fairness. This supports our self-activation hypothesis that stronger affective reactions to fairness-related events are more likely when people's selves have been activated.

The present line of research fits with recent developments in the justice literature that try to explain why fair and unfair events may impact on people's reactions (e.g., Brebels et al., 2008; Brockner, 2002; De Cremer \& Sedikides, 2005; De Cremer \& Tyler, 2005; Koper et al., 1993; Miedema, 2004; Sedikides et al., 2009; Van den Bos \& Lind, 2002; Van Prooijen, De Cremer, Van Beest, Stahl, \& Van Lange, 2008; Van Prooijen, Karremans, \& Van Beest, 2006; Van Prooijen \& Zwenk, 2009). These notions differ, but all suggest that fairness communicates important information about people's selves, and some recent papers have suggested that fairness may play an important role in affective self-regulatory processes, as a result of which people's affective reactions to fair and unfair events may be intimately associated with processes of self-regulation (Van den Bos, 2007; Van den Bos \& Lind, 2009; Van Prooijen \& Zwenk, 2009). The self-activation hypothesis proposed here was built on these lines of reasoning and the current findings, collected using different experimental paradigms, provide evidence supporting this hypothesis.

One noteworthy aspect of our findings is that both the fair and unfair conditions contributed to the significant interaction effects of the self-activation and fairness manipulations on participants' affective responses to the procedures and outcomes experienced. We also observe that in both studies we did not obtain reliable interactions on procedural or outcome fairness judgments. In line with earlier findings, this suggests that affective measures may be more susceptible for tapping interaction effects between self-regulatory antecedents and procedural or outcome manipulations (Miedema et al., 2006; Van den Bos, 2001; Van den Bos et al., 2005, 2008). Thus, our assumption is that interaction effects on fairness judgments would have been possible, but are less likely to be found than interactions on affective reactions, and especially negative affective responses to procedures and outcomes. Future research may want to investigate the difference and overlap between different affective responses and people's fairness judgments. For now, we conclude that our results underline that fairness and affect are different concepts, and we would applaud more research on this issue.

Related to this is the observation that although in both experiments overall correlations between fairness judgments and negative affect ratings were 
statistically significant (Experiment 1: $r=-.32, p<.01$; Experiment 2: $r=-.96$, $p<.001$ ), in both our experiments we found that within-cell correlations were only significant in the self-primed and unfair conditions (Experiment 1: self-salient and no-voice condition, $r=-.53, p<.01$; Experiment 2 : self-words and worse-thanother outcome condition, $r=-.90, p<.001)$. Within-cell correlations were not statistically significant in the other cells of our experimental designs. Combined with the main and interaction effects discussed earlier, this perhaps suggests that fairness judgments and negative affect ratings may be different concepts as they may respond quite differently toward manipulations of self-activation (yielding overall non-significant and significant interaction effects, respectively), but that fairness judgments and negative affect reactions are especially strongly intertwined under conditions of self-activation and unfairness. Future research is needed to examine in detail the implications of these findings.

We also note that the television condition in Experiment 1 may partially have activated people's selves, although in all likelihood less strongly so than in our selfsalient condition, as asking participants about their watching television constitutes a more indirect activation of the self than directly asking participants to think about themselves, as we did in the self-salient condition of Experiment 1. Furthermore, in our opinion, the subliminal manipulation used in Experiment 2, and the clear results that were obtained as a result of that manipulation, provide more definitive evidence for our self-activation hypothesis. Apparently, self-activation can unconsciously influence people's responses to fairness issues.

Stapel and Tesser (2001) report no significant influence of supraliminal selfactivation manipulations on ratings of personal uncertainty. What our participants wrote down following the salience manipulation of Experiment 1 is consistent with this observation, and it seems unlikely that the subliminal manipulation of Experiment 2 had an effect on such ratings or on measures related to people's selfthreats or alarming conditions. Thus, it seems probable that self-activation-rather than personal uncertainty (Van den Bos, 2001), self-threats (Miedema et al., 2006), or alarm-related processes (Van den Bos et al., 2008)—may have influenced participants' fairness reactions in the two experiments reported here.

In this paper we noted that personal uncertainty, self-threats, and events that are alarming to people may instigate different self-regulatory processes, but all have activation of the self in common. An important aim in this paper was to activate the self in a basic manner by means of supraliminal or subliminal manipulations that can be assumed to be independent of uncertainty concerns, threats, or alarming events, and to examine the effects of these manipulations on people's affective reactions to fair and unfair events. We seem to have been successful in achieving this aim. This said, we hasten to note here that personal uncertainty, self-threats, and other conditions that are alarming to people in all likelihood involve more than mere activation of people's selves, and in all likelihood all instigate related yet different processes. So, we are not suggesting that the mechanism of self-activation on enhanced affective responses to procedural and distributive fairness can explain all the effects of personal uncertainty, self-threat, and alarming situations that have been reported in the literature (see, e.g., De Cremer \& Sedikides, 2005; De Cremer \& Tyler, 2005; Sedikides et al., 2009), but we do suggest that self-activation is an 
important mechanism, involved in many reported findings and established fairness theories (see, e.g., Brockner \& Wiesenfeld, 1996; Tyler \& Lind, 1992; Van den Bos \& Lind, 2002).

In fact, it is our assumption that considerations of fairness, justice, and even ethics are not very important to people when the self is not activated. More precisely, we propose that when people witness unfair or unjust events, or cogitate about unethical practices, they do not have to be the victims of these unfair practices themselves, or be otherwise involved actively in these events, in order for them to be engaged with these issues. But this engagement, we argue, involves an activation of the self. In other words, issues of fairness, justice, and ethics activate people, stimulate them to take action, are upsetting or uplifting (Van den Bos \& Lind, 2002, 2009) because they touch core aspects of who we as humans are (see also Opotow, 1995). We note explicitly that this assumption is only that, an assumption, and that future research is needed to test all the implications that may follow from this notion. But if this assumption would turn out to be true then this may reveal that even unfair treatment of others can be upsetting because it activates important aspects of people's selves. This would yield new and more precise insights into the psychology of fairness, justice, and ethics.

Our argument does not imply that it is only the self-activation aspect of selfthreat, uncertainty, and alarm that leads people to react more strongly to fair and unfair events. Quite the contrary, we think that self-activation is a necessary condition before reliable fairness effects can be observed, but that typically the threat involved in experiences of personal uncertainty and other alarming events trigger strong hot cognitive reactions (Van den Bos, 2007) that go over and beyond the self-activation effects reported here (Van den Bos \& Lind, 2009). In fact, these threat aspects may instigate strong affective reactions in people, which may serve as important signals that self-regulatory processes are in order (Van den Bos, 2010). In other words, self-activation may be a necessary condition but not a sufficient condition to trigger the self-regulatory processes studied in the self-regulation literature (e.g., Vohs \& Baumeister, 2004) and the modern justice literature (e.g., Brebels et al., 2008; Sedikides et al., 2009; Van Prooijen \& Zwenk, 2009). Thus, the current findings suggest that simply activating the self (supraliminally or even subliminally) should be enough to increase fairness effects on affective reactions, but this does not imply that other issues (such as self-threat, uncertainty, and alarm) are not important and can not have effects over and beyond the basic effects of selfactivation reported here. More research is needed to examine in full the implications of this line of reasoning.

Furthermore, we want to note that activation of the self does not have to constitute an egocentric activation of the self. In other words, we are not suggesting that fairness concerns are a myth. Quite the contrary, we work from the assumption that fairness is frequently a very real concern to people (Van den Bos \& Lind, 2002; Van den Bos, Peters, Bobocel, \& Ybema, 2006; see also Miller, 1999; Miller \& Ratner, 1998). That said, we also think that researchers should thoroughly study the conditions under which fairness is more of a concern to people and when it is less important to them, as well as the processes underlying people's considerations of 
fairness. It is our hope that with this paper we have contributed a bit to what we see as the process-oriented future of the social psychology of justice and the self.

We also would applaud future research studies that would study explicitly the complex forms that self-activation may take. Our Experiment 2 and the findings obtained by Van Prooijen and Zwenk (2009; see also Van Prooijen et al., 2006, 2008) provide valuable information in this respect as they suggest that it may be especially the individual self that have a special role in understanding, explaining, and predicting people's reactions to fair and unfair events. Experiences of procedural justice and injustice are products of people's interactions with other people. This social nature of procedural justice has led researchers to conclude that it is the social self that shapes procedural fairness effects (see, e.g., De Cremer \& Tyler, 2005). Indeed, De Cremer (2002) found that procedural justice leads people to support the collective interest at the expense of immediate self-interest.

Van Prooijen and Zwenk (2009) argued, however, that these findings do not automatically imply that procedural fairness effects originate from concerns that are associated with the social self. For example, it is noteworthy that most procedural justice studies focus on individuals' reactions to fair and unfair procedures. Van Prooijen and Zwenk (2009; Van Prooijen et al., 2008) argued that individual recipients are likely to value the rewards that are associated with procedural justice (e.g., respect, admiration) because of the positive implications for their own feelings of self-worth, their own qualities, and their unique contributions to their community. Hence, it is plausible that the desire to obtain the rewards that are associated with procedural justice originate from the need to validate one's unique individual attributes. These considerations suggest that at least sometimes it is the individual self that constitutes the psychological basis for procedural fairness effects. This indeed would explain why even subliminal activation of the individual self leads to enhanced affective amplification regarding fair and unfair events, as we showed in the second experiment of this paper.

Some aspects of the self are obviously more directly related to justice and fairness than others and it would be interesting to assess whether activation of these different aspects may lead to different fairness reactions. Ultimately, this will yield an integrated theoretical model of self-activation regarding social justice. Related to this, self-regulation is a broad construct, so there are different potential ways in which self-activation potentially can influence reactions to injustice. For instance, it is known that self-activation can increase monitoring for discrepancies between standards and ongoing events, can lead to increased efforts to reduce such discrepancies, and can increase concerns with one's self-image (for an overview of the literature, see, e.g., Carver \& Scheier, 1998). Furthermore, future research might reveal that the self-activation procedures we used here linked the self to the subsequent scenarios or fairness experiences more strongly (i.e., increased their selfrelevance), which resulted in more extreme affective reactions because the scenarios or experiences were taken more seriously or garnered more attention. Finding evidence for this proposition would be in accordance with our line of reasoning, we think, and we would be quite excited if follow-up research would study this possible implication of our current findings. Insights into the social psychology of fairness 
reactions could be enhanced if more specific insights about the effects of selfactivation may be obtained in future research.

\section{Conclusions}

Fairness and the self are multi-faceted concepts that are likely to impact people's reactions for more than one reason. The current research suggests that a basic activation of the self (either supraliminal activation of the general self or subliminal activation of the individual self) is one such reason, perhaps a very fundamental reason. Because various concepts studied in the fairness literature may involve selfregulatory processes (Sedikides et al., 2009; Van den Bos \& Lind, 2002, 2009), this may imply that self-activation plays a crucial role in the social psychology of affective reactions to fair and unfair events. We hope that the current paper contributes to this hypothesis.

Acknowledgments We thank Diederik Stapel and Remco Wijn for their comments on earlier versions of this paper. This research was supported by an International Research Project Grant (400-10-030) and a VICI Innovational Research Grant (453-03-603); both grants obtained from the Netherlands Organization for Scientific Research.

Open Access This article is distributed under the terms of the Creative Commons Attribution Noncommercial License which permits any noncommercial use, distribution, and reproduction in any medium, provided the original author(s) and source are credited.

\section{References}

Abelson, R. P. (1963). Computer simulation of "hot cognitions". In S. S. Tomkins \& S. Messick (Eds.), Computer simulation and personality: Frontier of psychological theory (pp. 277-298). New York: Wiley.

Adams, J. S. (1965). Inequity in social exchange. In L. Berkowitz (Ed.), Advances in experimental social psychology (Vol. 2, pp. 267-299). New York: Academic Press.

Bargh, J. A., \& Chartrand, T. L. (2000). The mind in the middle: A practical guide to priming and automaticity research. In H. T. Reis \& C. M. Judd (Eds.), Handbook of research methods in social and personality psychology (pp. 253-285). Cambridge: Cambridge University Press.

Brebels, L., De Cremer, D., \& Sedikides, C. (2008). Retaliation as a response to procedural unfairness: A self-regulatory approach. Journal of Personality and Social Psychology, 95, 1511-1525.

Brewer, M. B., \& Gardner, W. (1996). Who is this "we"? Levels of collective identity and self representations. Journal of Personality and Social Psychology, 71, 83-93.

Brockner, J. (2002). Making sense of procedural fairness: High procedural fairness can reduce or heighten the influence of outcome favorability. Academy of Management Review, 27, 58-76.

Brockner, J., \& Wiesenfeld, B. M. (1996). An integrative framework for explaining reactions to decisions: Interactive effects of outcomes and procedures. Psychological Bulletin, 120, 189-208.

Carver, C. S., \& Scheier, M. F. (1998). On the self-regulation of behavior. New York: Cambridge University Press.

Coenen, M., Dijksterhuis, A., \& Wigboldus, D. (2003, February). Subliminal evaluative conditioning of existing attitudes. Poster presented at the Fourth Annual Meeting of the Society for Personality and Social Psychology, Los Angeles, USA.

Custers, R., \& Aarts, H. (2005). Positive affect as implicit motivator: On the nonconscious operation of behavioral goals. Journal of Personality and Social Psychology, 89, 129-142. 
De Cremer, D. (2002). Respect and cooperation in social dilemmas: The importance of feeling included. Personality and Social Psychology Bulletin, 28, 1335-1341.

De Cremer, D., \& Sedikides, C. (2005). Self-uncertainty and responsiveness to procedural justice. Journal of Experimental Social Psychology, 41, 157-173.

De Cremer, D., \& Tyler, T. R. (2005). Managing group behavior: The interplay between procedural justice, sense of self, and cooperation. In M. P. Zanna (Ed.), Advances in experimental social psychology (Vol. 37, pp. 151-218). San Diego, CA: Academic Press.

Eisenberger, N. I., Lieberman, M. D., \& Williams, K. D. (2003). Does rejection hurt? An fMRI study of social exclusion. Science, 302, 290-292.

Folger, R., \& Cropanzano, R. (1998). Organizational justice and human resource management. Thousand Oaks, CA: Sage.

Gardner, W. L., Gabriel, S., \& Lee, A. Y. (1999). "I" value freedom, but "we" value relationships: Selfconstrual priming mirrors cultural differences in judgments. Psychological Science, 10, 321-326.

Koper, G., Van Knippenberg, D., Bouhuijs, F., Vermunt, R., \& Wilke, H. (1993). Procedural fairness and self-esteem. European Journal of Social Psychology, 23, 313-325.

Miedema, J. (2004). Fairness and the self. Doctoral dissertation, Leiden University.

Miedema, J., Van den Bos, K., \& Vermunt, R. (2006). The influence of self-threats on fairness judgments and affective measures. Social Justice Research, 19, 228-253.

Miller, D. T. (1999). The norm of self-interest. American Psychologist, 54, 1053-1060.

Miller, D. T., \& Ratner, R. K. (1998). The disparity between the actual and assumed power of selfinterest. Journal of Personality and Social Psychology, 74, 53-62.

Opotow, S. (1995). Drawing the line: Social categorization, moral exclusion, and the scope of justice. In B. B. Bunker \& J. Z. Rubin (Eds.), Conflict, cooperation, and justice: Essays inspired by the work of Morton Deutsch (pp. 347-369). San Francisco: Jossey-Bass.

Sedikides, C., De Cremer, D., Hart, C. M., \& Brebels, L. (2009). Procedural fairness responses in the context of self-uncertainty. In R. M. Arkin, K. C. Oleson, \& P. J. Carroll (Eds.), Handbook of the uncertain self (pp. 142-159). New York: Psychology Press.

Stapel, D. A. (2003). Hot cognition and social judgments: When and why do descriptions influence our feelings? In J. P. Forgas, K. P. Williams, \& W. Von Hippel (Eds.), Social judgments: Implicit and explicit processes (pp. 227-250). Cambridge: Cambridge University Press.

Stapel, D. A., \& Koomen, W. (2001). I, we, and the effects of others on me: How self-construal level moderates social comparison effects. Journal of Personality and Social Psychology, 80, 766-781.

Stapel, D. A., \& Tesser, A. (2001). Self-activation increases social comparison. Journal of Personality and Social Psychology, 81, 742-750.

Tyler, T. R., \& Lind, E. A. (1992). A relational model of authority in groups. In M. P. Zanna (Ed.), Advances in experimental social psychology (Vol. 25, pp. 115-191). San Diego, CA: Academic Press.

Tyler, T. R., \& Smith, H. J. (1998). Social justice and social movements. In D. Gilbert, S. T. Fiske, \& G. Lindzey (Eds.), The handbook of social psychology (4th ed., Vol. 2, pp. 595-629). Boston: McGrawHill.

Van den Bos, K. (2001). Uncertainty management: The influence of uncertainty salience on reactions to perceived procedural fairness. Journal of Personality and Social Psychology, 80, 931-941.

Van den Bos, K. (2007). Hot cognition and social justice judgments: The combined influence of cognitive and affective factors on the justice judgment process. In D. de Cremer (Ed.), Advances in the psychology of justice and affect (pp. 59-82). Greenwich, CT: Information Age Publishing.

Van den Bos, K. (2010). Self-regulation, homeostasis, and behavioral disinhibition in normative judgments. In D. R. Bobocel, A. C. Kay, M. P. Zanna, \& J. M. Olson (Eds.), The psychology of justice and legitimacy: The Ontario Symposium (Vol. 11, pp. 205-228). New York: Psychology Press.

Van den Bos, K., Bruins, J., Wilke, H. A. M., \& Dronkert, E. (1999). Sometimes unfair procedures have nice aspects: On the psychology of the fair process effect. Journal of Personality and Social Psychology, 77, 324-336.

Van den Bos, K., Ham, J., Lind, E. A., Simonis, M., Van Essen, W. J., \& Rijpkema, M. (2008). Justice and the human alarm system: The impact of exclamation points and flashing lights on the justice judgment process. Journal of Experimental Social Psychology, 44, 201-219.

Van den Bos, K., Heuven, E., Burger, E., \& Fernández Van Veldhuizen, M. (2006). Uncertainty management after reorganizations: The ameliorative effect of outcome fairness on job uncertainty. International Review of Social Psychology, 19, 75-86. 
Van den Bos, K., \& Lind, E. A. (2002). Uncertainty management by means of fairness judgments. In M. P. Zanna (Ed.), Advances in experimental social psychology (Vol. 34, pp. 1-60). San Diego, CA: Academic Press.

Van den Bos, K., \& Lind, E. A. (2009). The social psychology of fairness and the regulation of personal uncertainty. In R. M. Arkin, K. C. Oleson, \& P. J. Carroll (Eds.), Handbook of the uncertain self (pp. 122-141). New York: Psychology Press.

Van den Bos, K., Peters, S. L., Bobocel, D. R., \& Ybema, J. F. (2006). On preferences and doing the right thing: Satisfaction with advantageous inequity when cognitive processing is limited. Journal of Experimental Social Psychology, 42, 273-289.

Van den Bos, K., Poortvliet, P. M., Maas, M., Miedema, J., \& Van den Ham, E.-J. (2005). An enquiry concerning the principles of cultural norms and values: The impact of uncertainty and mortality salience on reactions to violations and bolstering of cultural worldviews. Journal of Experimental Social Psychology, 41, 91-113.

Van Prooijen, J.-W., De Cremer, D., Van Beest, I., Stahl, T., \& Van Lange, P. A. M. (2008). The egocentric nature of procedural justice: Social value orientation as moderator of reactions to decision-making procedures. Journal of Experimental Social Psychology, 44, 1303-1315.

Van Prooijen, J.-W., Karremans, J. C., \& Van Beest, I. (2006). Procedural justice and the hedonic principle: How approach versus avoidance motivation influences the psychology of voice. Journal of Personality and Social Psychology, 91, 686-697.

Van Prooijen, J.-W., \& Zwenk, F. (2009). Self-construal level and voice procedures: The individual self as psychological basis for procedural fairness effects. Journal of Experimental Social Psychology, 45, 392-397.

Vohs, K. D., \& Baumeister, R. F. (2004). Understanding self-regulation: An introduction. In R. F. Baumeister \& K. D. Vohs (Eds.), Handbook of self-regulation: Research, theory, and applications (pp. 1-12). New York: The Guilford Press.

Watson, D., Clark, L. A., \& Tellegen, A. (1988). Development and validation of brief measures of positive and negative affect: The PANAS scales. Journal of Personality and Social Psychology, 54, 1063-1070. 